\title{
THE OXFORD CLUB-FOOT PROGRAMME
}

\author{
S. B. TIBREWAL, M. K. D. BENSON, C. HOWARD, †D. J. FULLER \\ From the Nuffield Orthopaedic Centre, Oxford
}

\begin{abstract}
We treated 63 club feet in 44 patients by a defined programme of strapping from birth followed by one of two operations performed at six weeks, either a simple calcaneal tendon lengthening or a subtalar realignment, and reviewed them prospectively. The decision as to which operation to perform was taken at four weeks after radiographic measurement of the talocalcaneal angle. All but eight patients (ten feet) were followed for a mean of 8.7 years. The overall results after calcaneal tendon lengthening were satisfactory. The re-operation rate after subtalar realignment was high (39\%) due to over or undercorrection of the deformity.
\end{abstract}

One problem in the treatment of congenital talipes equinovarus (CTEV) is the lack of a quantifiable system for classifying the deformity. The assessment of alternative treatments has been presented in such varying ways by different authors that it is almost impossible to compare them. The late D. J. Fuller believed that there was a clear need for a prospective study in which all children with this condition should be seen and managed from birth by one surgeon following a rigidly defined protocol. We present the results of his treatment programme.

\section{PATIENTS AND METHODS}

Programme. Each club foot was examined at birth by one consultant orthopaedic surgeon (DJF). Photographs and clinical notes recorded the severity of the three elements of the deformity, ankle equinus, hindfoot varus and forefoot hooking. The feet were treated immediately by the application of strapping and gentle manipulation by the mother. The strapping was changed twice weekly for the first two weeks and then once a week for the next two weeks. Every foot was strapped by DJF personally or by

S. B. Tibrewal, FRCS, FICS, Consultant Orthopaedic Surgeon Greenwich District Hospital, London, SE10 9HE, England.

M. K. D. Benson, FRCS, Consultant Orthopaedic Surgeon Nuffield Orthopaedic Centre, Oxford OX3 7LD, England.

C. Howard, FRCS, Orthopaedic Surgeon

1 Sigalon Street, POB 540, Omer, Israel.

†D. J. Fuller, deceased, MS, FRCS

Correspondence should be sent to Mr S. B. Tibrewal.

(C) 1992 British Editorial Society of Bone and Joint Surgery $0301-620 X / 92 / 4375 \$ 2.00$

J Bone Joint Surg [Br] 1992; 74-B :528-33. a senior physiotherapist who supervised the day-to-day management of the patients throughout the five years of the study.

After one month of strapping, the feet were assessed. Further photographs were taken and the improvement achieved was recorded. Hindfoot equinus and mobility were measured clinically but the degree of heel varus was determined by the following radiographic technique.

Anteroposterior radiographs were taken with the foot held in $20^{\circ}$ of equinus and with the sole on the cassette (Davis and Hatt 1955). If the ossific centres of the talus and the calcaneum appeared to be separate and diverging (a talocalcaneal angle of more than $25^{\circ}$ ) significant hindfoot varus was excluded (Fig. 1a). If the centres overlapped (Fig. 1b), it was concluded that the calcaneum lay in varus beneath the talus (Simons 1977). Surgical treatment. Further treatment was planned for each child at the age of one month. Three possibilities were considered (Fig. 2):

1) if the foot was fully corrected, no further treatment was needed;

2) if there was persisting equinus without radiological evidence of hindfoot varus, lengthening of the calcaneal tendon was indicated; and

3) if there was radiographic evidence of varus, even without clinical evidence, a subtalar realignment procedure (STR) and lengthening of the calcaneal tendon were performed.

Strapping was continued until the children were admitted for surgery at six weeks of age.

Calcaneal tendon lengthening. Z-lengthening of the calcaneal tendon was performed through a posterior longitudinal incision. The cut tendon ends were laid side by side but not sutured in about half the patients; in the other half the ends were sutured. The foot was immobilised in 


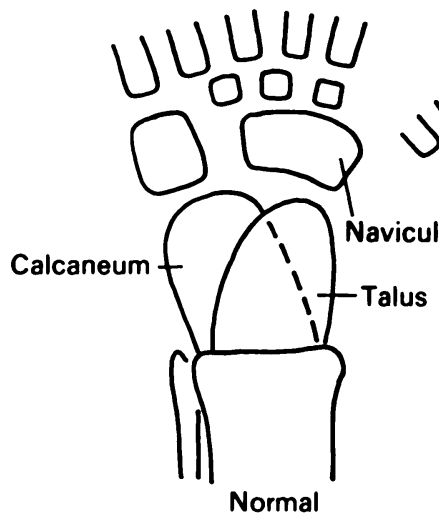

Fig. la

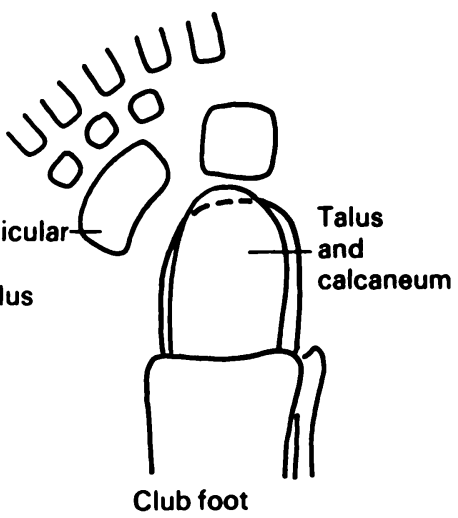

Fig. 1b
Diagrammatic representation of the ossified nuclei of the talus and the calcaneum in a normal foot and one with hindfoot varus. an above-knee plaster cast in the corrected position for six weeks after surgery.

Subtalar realignment. This operation was performed through a posteromedial incision (Fig. 3). The neurovascular bundle was freed and isolated and the extensor hallucis longus and extensor digitorum longus and the tibialis posterior tendons were elongated in a ' $Z$ ' fashion, as was the calcaneal tendon. The superficial part of the deltoid ligament was divided. The subtalar joint was opened posteriorly (where it is easiest to find) and then medially and distally as far as the talonavicular joint. The talocalcaneal interosseous ligaments were divided and the lateral subtalar capsule and the lateral calcaneofibular ligaments released, thereby allowing the calcaneum to be pulled away from the talus and repositioned more normally. This movement of the calcaneum took

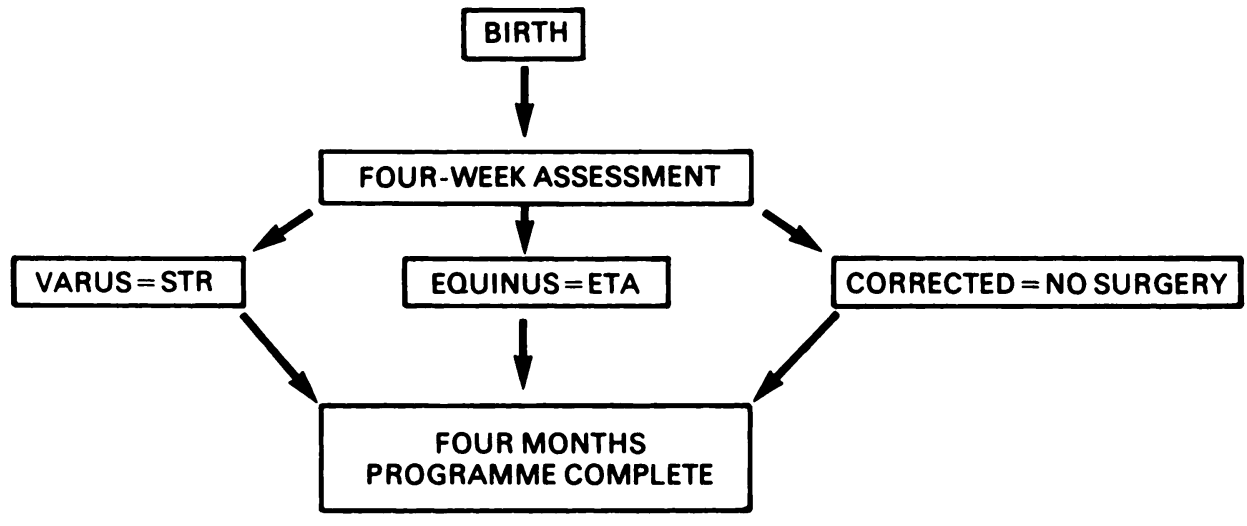

Fig. 2

The treatment programme. STR = Subtalar realignment. ETA = lengthening of calcaneal tendon.
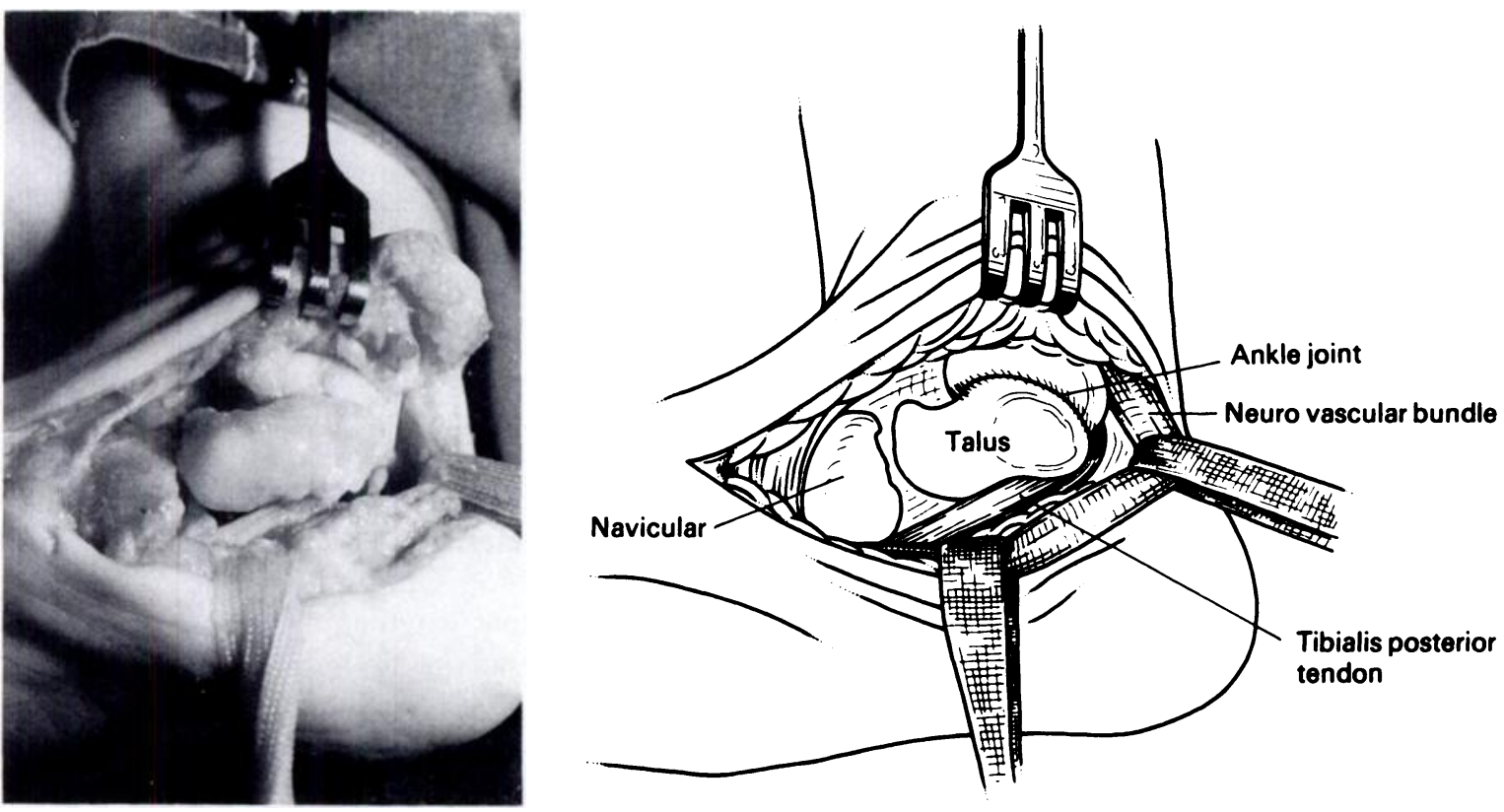

Fig. 3

The surgical approach for subtalar realignment. 
the remainder of the foot with it and the subluxed talonavicular joint was automatically realigned. No plantar release was performed and the ankle capsule was not divided.

Although the talus was of abnormal shape and disposition, it remained the reference point around which the heel was repositioned. The aim was to produce a plantigrade foot, not (unrealistically) a normal foot. With the calcaneum carefully positioned underneath the talus, the bones were transfixed by two Kirschner wires passed upward through the heel and the subtalar joint. Overcorrection was not the purpose of the operation. A wellpadded long-leg plaster cast was worn until the wires were removed three weeks later. A further plaster cast was then applied and worn for three weeks. In patients in whom the surgical wound could not be fully closed, granulation tissue and a new epithelium developed quickly and all wounds were fully healed when the casts were removed.

No further treatment was offered after the cast was removed. The entire treatment programme therefore consisted of strapping for six weeks, one operation and a long-leg plaster for six weeks, even for the most severe cases. Follow-up was at three-monthly intervals until the age of one year and at six-monthly intervals thereafter.

Assessment. The study included 63 club feet in 44 patients. Ten feet (eight patients) were lost to follow-up, leaving 53 feet in 36 patients ( 27 male, nine female). Elongation of the calcaneal tendon had been performed on 25 of these feet and subtalar realignment on 28 . The patients were followed up for an average of 8.7 years (range 7 to 12 ) in a special clinic where clinical, photographic and radiographic assessments were made.

Table I. Grading of equinus and varus deformities, and of hindfoot mobility

\begin{tabular}{lllll}
\hline \multicolumn{3}{l}{ Grade } & 2 & 3 \\
\cline { 2 - 5 } Equinus & Nil & Tightness & $\begin{array}{l}\text { Heel strike } \\
\text { reduced or } \\
\text { absent }\end{array}$ & $\begin{array}{l}\text { Heel high and } \\
\text { fixed }\end{array}$ \\
Varus & Nil & $\begin{array}{l}\text { Less than } 10^{\circ} \\
\text { on weight- } \\
\text { bearing with } \\
\text { plantigrade } \\
\text { foot }\end{array}$ & $\begin{array}{l}\text { More than } 10^{\circ} \\
\text { with } \\
\text { plantigrade } \\
\text { weight-bearing } \\
\text { foot }\end{array}$ & $\begin{array}{l}\text { Fixed varus } \\
\text { with weight- } \\
\text { bearing on } \\
\text { outer foot }\end{array}$ \\
$\begin{array}{l}\text { Mobility of } \\
\text { hindfoot }\end{array}$ & Full & Reduced & Minimal & Totally stiff \\
\hline
\end{tabular}

The clinical evaluation measured equinus, varus and hindfoot mobility (Table I). Functional assessment included the occurrence of pain, limitation of activity, shoe wear and ability to walk on tiptoe. The talocalcaneal angle and talocalcaneal index (Beatson and Pearson 1966) were determined radiographically.

In the treatment programme as defined, only two feet with true CTEV appeared to have been corrected initially without any surgery. These feet are not included in the assessment of results.

\section{RESULTS}

Final results will not be available until these children have reached maturity. We report our observations at a minimum follow-up of seven years.

We believe that there is no overlap between true CTEV and common postural equinovarus which has not been included in this series. All our cases were true club feet and with the passage of time the characteristic stigmata of that condition have developed, confirming the diagnosis in all cases. At primary presentation there were no features which predicted those deformities which would respond to early strapping.

Failures. The patients who had an unsatisfactory result from primary surgery and were re-operated on were classified as failures.

Calcaneal tendon lengthening. Of the 25 feet treated by calcaneal tendon lengthening, six required further surgery for recurrence or undercorrection of the deformity. In one patient with Down's syndrome a subtalar realignment was necessary at the age of 4.5 years. Three feet required forefoot and medial release for persistent forefoot hooking and cavus, and two tibialis anterior transfer to improve dorsiflexion. None of the feet treated initially by calcaneal tendon lengthening was overcorrected.

Subtalar realignment. Eleven of the 28 feet in this group required a further operation for undercorrection, recurrence or overcorrection of the deformity.

Two feet underwent repeat subtalar realignment and two had calcaneal osteotomy for recurrence of varus deformity at five years. One patient had bilateral external rotation tibial osteotomies to correct intoeing five years after the initial surgery. Several further operations were required for infected nonunion on one side of this patient but the result was eventually satisfactory in terms of function and alignment. Three feet required tibialis anterior transfers at six years and are now asymptomatic.

Two feet underwent calcaneal osteotomy for excessive valgus due to overcorrection, one at two years and the other at seven years. One of these patients later required anterior ankle release to correct a rigid calcaneus deformity. Examination confirmed that these feet took weight predominantly through the heel (Fig. 4).

Outcome. The outcome is described for all 53 feet, including the failures detailed above.

Equinus recurrence. One foot in the group treated by calcaneal tendon lengthening had residual grade 1 equinus and two in the group treated by subtalar realignment had residual grade 1 calcaneus deformities. Varus recurrence. In those treated by calcaneal tendon lengthening, one foot had a grade 1 varus heel. In the subtalar realignment group there were six with grade 1 varus heels and one with minimal valgus overcorrection. Hindfoot mobility. No feet were completely stiff but most 


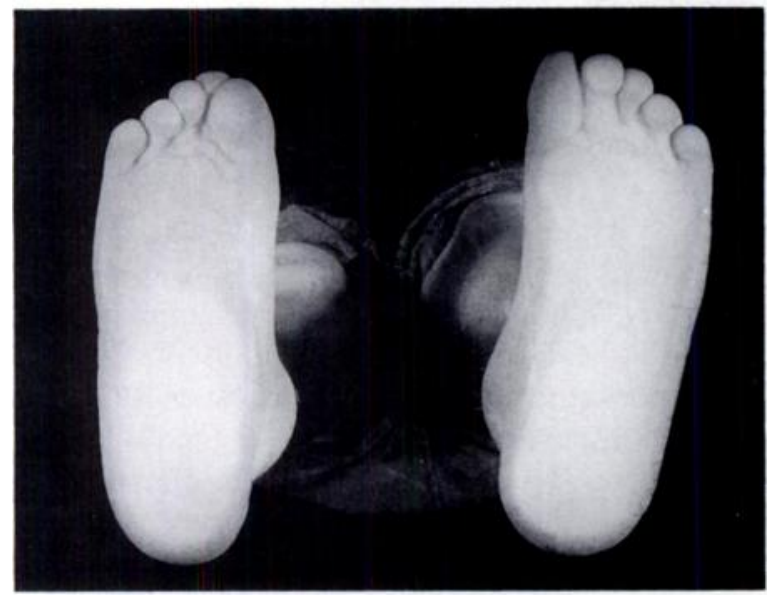

Fig. 4

Weight-bearing pattern in overcorrected calcaneus feet.

lost some mobility (Table II). Only one foot in the subtalar realignment group had full mobility. Five had only minimal movement; three of these had had additional surgery. Six feet in the calcaneal tendon lengthening group had full mobility and none had grade 2 or 3 mobility. The remaining feet had grade 1 mobility. Forefoot deformities. The incidences of residual deformities of the arch, forefoot adduction and rotation are given in Table III.

Radiographic analysis. The talocalcaneal indices (Beatson and Pearson 1966) measured on the follow-up radiographs did not differ between the two treatment groups (average $=55^{\circ}$ for the tendon-lengthening group and $61^{\circ}$ for the subtalar realignment group). The navicular appeared

Table II. Flexibility of feet in the two treatment groups. Pre-operatively the feet were classified simply as flexible or stiff and postoperatively stiffness was graded 0 to 3

\begin{tabular}{|c|c|c|c|c|c|c|}
\hline \multirow[b]{3}{*}{ Treatment group } & \multicolumn{6}{|l|}{ Grade } \\
\hline & \multicolumn{2}{|c|}{ Pre-operative } & \multicolumn{4}{|c|}{ Postoperative } \\
\hline & Flexible & Stiff & $\mathbf{0}$ & 1 & 2 & 3 \\
\hline ETA $(n=25)$ & 23 & 2 & 6 & 19 & 0 & 0 \\
\hline STR $(n=28)$ & 11 & 17 & 1 & 22 & 5 & 0 \\
\hline
\end{tabular}

* ETA. elongation of the calcaneal tendon: STR, subtalar realignment wedge-shaped in $70 \%$ of the latter group and in none of the former. Some flattening of the talus was invariably seen.

Pain. No patient complained of pain when walking. Two had occasional aching after strenuous activities.

Limitation of activity. Thirty patients $(83 \%)$ had no limitation of their activity. Four patients $(11 \%)$ complained of slight limitation and two $(6 \%)$ were unable to play sport due to discomfort in the operated feet.

Tiptoe standing. No correlation was found between the sutured and non-sutured tendons and the patients' ability to stand on tiptoe; $65 \%$ of patients of the tendonlengthened group and $46 \%$ of the subtalar realignment group were able to stand on tiptoe with the knee extended. Shoe wear. Twelve feet in $33 \%$ of the patients required a smaller size shoe; five were two sizes smaller than the normal size, two were one size smaller and five were a half size smaller. The other patients were able to wear shoes of the same size although often with toe-block insoles.

\section{DISCUSSION}

In this series the entire treatment programme was completed in three months. It included strapping for six weeks only, one operation and six weeks in a plaster cast, even for the most severe cases.

Early assessment of the deformity and an early surgical approach have made it feasible to separate simple hindfoot equinus from equinovarus deformities, the radiographs at four weeks allowing identification of hidden hindfoot varus (Fig. 5). The outcome of those treated by simple calcaneal tendon release has been encouraging. The reoperation rate in this group has been small and reasonable mobility has been retained after surgery. In those who did require a second operation the final result was satisfactory.

None of the reoperations in this group was for the correction of hindfoot varus deformity. This confirms that early differentiation by measurement of the talocalcaneal angle can distinguish a group of children who can be successfully treated by posterior surgery alone.

The results of radical subtalar realignment have been less satisfactory, although no worse than some other series (Laaveg and Ponseti 1980; Thompson, Richardson and Westin 1982; Ghali et al 1983; Green and LloydRoberts 1985; Hutchins et al 1985). They represent the

Table III. Number (and percentage) of feet in the two treatment groups with residual forefoot deformity

\begin{tabular}{|c|c|c|c|c|c|c|c|c|c|}
\hline \multirow{2}{*}{$\begin{array}{l}\text { Treatment } \\
\text { group* }\end{array}$} & \multicolumn{3}{|c|}{ Arch shape } & \multicolumn{3}{|c|}{ Forefoot adduction } & \multicolumn{3}{|l|}{ Rotation } \\
\hline & Cavus & Neutral & Planus & Adduction & Neutral & Abduction & Neutral & Supinated & Pronated \\
\hline ETA & $10(40)$ & $15(60)$ & 0 & $11(44)$ & $14(56)$ & 0 & $8(32)$ & $17(68)$ & 0 \\
\hline STR & $16(57)$ & $8(29)$ & $4(14)$ & $18(64.5)$ & $8(28.5)$ & $2(7)$ & $12(43)$ & $13(46)$ & $3(11)$ \\
\hline
\end{tabular}

* ETA, elongation of the calcaneal tendon, STR, subtalar realignment 


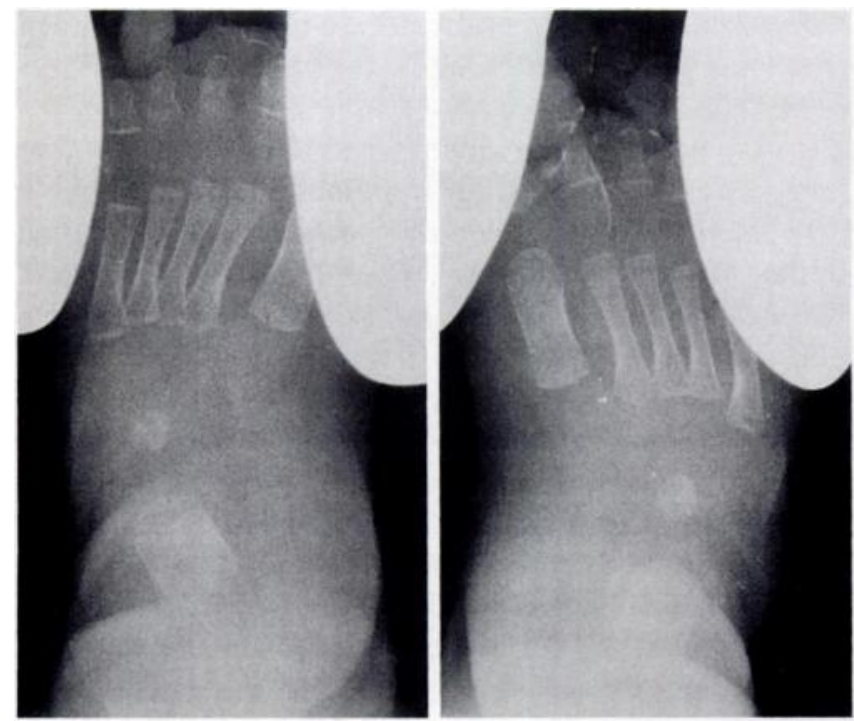

Fig. 5

Anteroposterior radiographs of both feet of one infant. On the left the overlapping ossific centres of the talus and calcaneum contrast with the normally divergent talocalcaneal angle on the right. There was good correction and function eight years after elongation of the calcaneal tendon on the right and subtalar realignment on the left.

so-called 'resistant' group of club feet; their reoperation rate of approximately $39 \%$ compares favourably with that of some other series (Main et al 1977; Harrold and Walker 1983). Some authors believe that wide subtalar realignment is unnecessary (Goldner 1988; Yngve, Gross and Sullivan 1990) and cases of overcorrection did occur during the first year of our programme, two of them requiring radical revision surgery. Simons $(1985 a, b)$ reported overcorrection in three of 26 feet treated by posteromedial and lateral release and five of 25 feet treated by complete subtalar realignment. The overcorrected foot is a serious problem.

Our reoperation rate after subtalar realignment is higher than that reported by Simons $(1985 a, b)$ but a direct comparison between the two series is not possible as Simons' follow-up was much shorter (2 to 3.5 years). Most of the reoperations in our series were required five to six years after the initial operation which often appeared at first to have been successful. The use of intraoperative radiographs to verify the degree of correction as suggested by Simons $(1985 \mathrm{a}, \mathrm{b})$ appears attractive and may decrease the frequency of over and undercorrection.

Eight patients in the tendon-lengthening group and 15 in the subtalar realignment group were unable to stand on tiptoe with the knee extended. No correlation was found between the sutured and non-sutured subgroups in this respect.

Stiffness was a problem in the subtalar realignment group but many of these feet were stiff to start with. Preoperative measurements of deformity and mobility should be compared with postoperative values. We have been able to compare the pre-operative mobility, varus and equinus figures with the postoperative results but cavus, adductus and rotation were not measured preoperatively.

The very posterior position of the heel scar after subtalar realignment was considered to be less than satisfactory. The advantages of the Cincinnati incision (Crawford, Marxen and Osterfeld 1982) have been recently confirmed (Brougham and Nicol 1988) and it can be recommended for future use.

As there is no conformity in the management of CTEV and a lack of agreed criteria it is almost impossible to make comparisons between series. Some studies consider only children treated from birth (Ryöppy and Sairanen 1983) and others include children of several ages (Green and Lloyd-Roberts 1985) and after different initial treatments (Turco 1979). Some report functional results, others the cosmetic appearance, and some categorise patients into 'satisfactory' and 'unsatisfactory' groups. Many authors have used a point system (Laaveg and Ponseti 1980; Ghali et al 1983) but this too has its difficulties as pointed out by Tayton and Thompson (1979). Catterall (1991) has recently described another method of assessment of the club-foot deformity.

Most series have reported good functional results independently of the objective outcome and irrespective of the method of assessment. We believe that objective criteria should be analysed and reported in a simple way to make comparison between series easier. If the foot is satisfactory in every parameter then we can claim a successful outcome. It is inappropriate to add different scores as this makes comparison between different treatment programmes difficult.

The authors would like to dedicate this paper to the memory of D. J. Fuller, tragically killed in 1983 . They would also like to thank Ms Leigh Bryan for her secretarial assistance.

No benefits in any form have been received or will be received from a commercial party related directly or indirectly to the subject of this article.

\section{REFERENCES}

Beatson TR, Pearson JR. A method of assessing correction in club feet. $J$ Bone Joint Surg [Br] 1966; 48-B:40-50.

Brougham DI, Nicol RO. Use of the Cincinnati incision in congenital talipes equino varus. J Pediatr Orthop 1988; 8:696-8.

Catterall A. A method of assessment of the clubfoot deformity. Clin Orthop $1991 ; 264: 48-53$.

Crawford AH, Marxen JL, Osterfeld DL. The Cincinnati incision : a comprehensive approach for surgical procedures of the foot and ankle in childhood. J Bone Joint Surg [Am] 1982; 64:1355-8.

Davis LA, Hatt WS. Congenital abnormalities of the feet. Radiology $1955 ; 64: 818-25$.

Ghali NN, Smith RB, Clayden AD, Silk FF. The results of pantalar reduction in the management of congenital talipes equinovarus. $J$ Bone Joint Surg [Br] 1983; 65-B:1-7. 
Goldner JL. Extensive subtalar arthrotomy is unnecessary in the surgical treatment of congenital club foot. J Bone Joint Surg [Br] 1988; 70B: 506 .

Green ADL, Lloyd-Roberts GC. The results of early posterior release in resistant club feet. J Bone Joint Surg [ Br] 1985; 67-B:588-93.

Harrold AJ, Walker CJ. Treatment and prognosis in congenital club foot. J Bone Joint Surg [ Br] 1983; 65-B :8-11.

Hutchins PM, Foster BK, Paterson DC, Cole EA. Long-term results of early surgical release in club feet. J Bone Joint Surg [Br] 1985; 67 B: $791-9$.

Laaveg SJ, Ponseti IV. Long term results of treatment of club foot. $J$ Bone Joint Surg [ Am] 1980; 62-A :23-31.

Main BJ, Crider RJ, Polk M, et al. The results of early operation in talipes equino-varus: a preliminary report. J Bone Joint Surg [Br] 1977; 59-B:337-41.

Ryöppy S, Sairanen H. Neonatal operative treatment of club foot: a preliminary report. J Bone Joint Surg [Br] 1983; 65-B:320-5.
Simons GW. Analytical radiography of club feet. J Bone Joint Surg [Br] 1977; 59-B:485-9.

Simons GW. Complete subtalar release in club feet. Part I. A preliminary report. J Bone Joint Surg [ Am] 1985a; 67-A :1044-55.

Simons GW. Complete subtalar release in club feet. Part II. Comparison with less extensive procedures. J Bone Joint Surg [Am] 1985b; 67 A : $1056-65$.

Tayton KJJ, Thompson P. Relapsing club feet: late results of delayed operation. J Bone Joint Surg [Br] 1979; 61-B:474-80.

Thompson GH, Richardson AB, Westin GW. Surgical management of resistant congenital talipes equinovarus deformities. $J$ Bone Joint Surg [ Am] 1982; 64-A :652-65.

Turco VJ. Resistant congenital club foot - one stage posteromedial release with internal fixation: a follow-up report of a fifteen-year experience. J Bone Joint Surg [ Am] 1979; 61-A :805-14.

Yngve DA, Gross RH, Sullivan JA. Clubfoot release without wide subtalar release. J Pediatr Orthop 1990; 10:473-6. 